\title{
Hygroscopic expansion: A key point to describe natural fibre/polymer matrix interface bond strength
}

\author{
le Duigou Antoine ${ }^{1,{ }^{*}}$, Merotte Justin ${ }^{1,3}$, Bourmaud Alain ${ }^{1}$, Davies Peter ${ }^{2}$, Belhouli Karim ${ }^{3}$, \\ Baley Christophe ${ }^{1}$
}

${ }_{1}^{1}$ Polymer and Composites, Univ. Bretagne Sud, FRE CNRS 3744, IRDL, France

2 Ifremer, Marine Structures Group, Centre de Bretagne, BP 70, 29280, Plouzané, France

${ }^{3}$ EcoTechnilin SAS, F-76190, Valliquerville, France

* Corresponding author : Antoine le Duigou, email address : antoine.le-duigou@univ-ubs.fr

\begin{abstract}
:
The present article aims to investigate the contribution of hygroscopic expansion of flax fibres to interfacial radial stresses and Interfacial Shear Strength (IFSS) of Maleic Anhydride grafted PolyPropylene (MAPP)/Flax biocomposites.

During manufacturing of thermoplastic biocomposites and storage at $50 \% \mathrm{RH}$, a weight variation is observed, attributed to water content evolution within plant cell-walls. The hygroscopic radial expansion coefficient $\beta r$ flax of single flax fibres estimated by Environmental Scanning Electron Microscopy (ESEM) observation is many orders of magnitude higher $(\beta f, R=1.14 \varepsilon / \Delta m$ ) than thermal expansion (af, $R=7810-6 \varepsilon /{ }^{\circ} \mathrm{C}$ ). Thus, its contribution to the development of residual stresses orad during processing should be prevalent. A multiscale analysis of interfacial stress state and hygroscopic contribution is performed with the use of a cylindrical concentric model at microscopic scale and asymmetric composite laminates $\left[0,90^{\circ}\right]$ curvature generation at macroscopic scale. Similar radial stresses are obtained, while

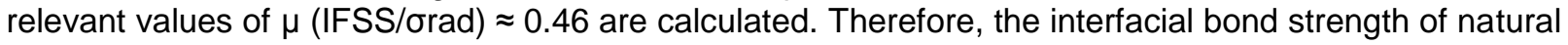
fiber/polymer systems should be described by taking into account their hygroscopic behavior.
\end{abstract}

Keywords : Flax fibres, Fibre/matrix bond 
29 Interfacial bond strength in fibre/matrix composite systems is typically produced by

30 several complex mechanisms such as mechanical anchorage, chemical bonding,

31 interdiffusion and so on. For thermoplastic polymer where low chemical bonding is

32 expected, residual stresses that arise from thermal mismatch between components $(\Delta \alpha)$

33 make a major contribution to interfacial bond strength [1] [2].

34 Bast fibres such as flax are increasingly used for composite reinforcement due to their

35 high specific stiffness [3]. However, the natural fibre/polymer interfacial bond strength

36 is often considered as a limitation for biocomposites. Thomason et al [4] suggest that

37 fibre anisotropy and high thermal radial expansion lower thermal mismatch and

38 interfacial shear strength. Indeed, plant fibres such as flax exhibit 15 times higher

39 transverse thermal expansion coefficients than glass fibres $\left(\alpha_{\mathrm{fL} f l a x}=2.810^{-6} /{ }^{\circ} \mathrm{C} ; \alpha_{\mathrm{fT} f l a x}=\right.$

$407810^{-6} /{ }^{\circ} \mathrm{C}[5]$ and $\alpha_{\mathrm{fT}}$ glass $=510^{-6} /{ }^{\circ} \mathrm{C}$ [5]). Similar ideas were proposed by Morgan et al

41 [6] to explain low IFSS with Kevlar fibres for which the thermal expansion coefficient

42 is 10 times lower than that of glass $\left(\alpha_{\mathrm{fT} \text { kevlar }}=5010^{-6} /{ }^{\circ} \mathrm{C}[5]\right)$.

43 However, numerous studies using microbond tests have underlined that plant fibres

44 show satisfactory IFSS levels with PLA [7][8][9][10], PA11 [11], Epoxy [12] or 
45 Polyester [13] with a high contribution of frictional stress and thus residual stresses after 46 debonding [11][10].

47 Basically, the static friction coefficients $\mu$, obtained from the ratio between interfacial tangential stress (IFSS) and normal stress (radial residual stress) is expressed by a

combination of a molecular adhesion component of the frictional force and a deformation component caused by the introduction of microroughness [14].

From previous calculations based on a micromechanical analysis [11], the static friction coefficient $\mu$ for PA 11/flax systems was found to give an anomalous value of 5.5 when only thermal residual stresses were taken into account. A similar result has been published by Thomason et al [15] on glass epoxy/systems while expected values should be around 0.5 [16] [17]. Thomason et al [15] have shown that when cure shrinkage stresses are added to residual thermal values to describe residual stresses, $\mu$ reaches more realistic values around 0.6.This underlines that a complete description of residual stress sources is essential. Thus, for the present work, the IFSS of plant fibres in composites does not to appear to be correctly described by thermal expansion alone, and other sources of residual stresses should be investigated.

Experimental techniques to estimate residual stresses have been reviewed by Parlevliet et al [18]. Among them, asymmetric laminates provide a simple indirect indication of residual stress by out-of-plane deformation i.e. warpage. Such laminates have been used for example to reveal hygrothermal [19] and curing stresses [20]. For natural fibres, during water immersion, curvature of asymmetric flax/PP laminates has been observed so that hygroscopic radial stresses around fibres were highlighted [21][22]. Almgren et al. claim that hygroscopic stresses could enhance IFSS [23]. 
68 The purpose of the present article is to evaluate the contribution of hygroscopic

69

70 expansion of flax fibres on IFSS as previously only the thermal contribution was taken into account in the literature. First, water content within flax fibres will be monitored throughout the manufacturing and storage steps by gravimetric measurements. Then, hygroscopic coefficient $\beta_{\mathrm{r} \text {, flax }}$ of a single flax fibre will be evaluated using ESEM measurements together with sorption isotherms from the literature. A multiscale evaluation of radial stresses and the contribution of the hygroscopic radial stress will be made. At the microscopic scale, residual stresses (thermal and hygroscopic) will be evaluated by a micromechanical approach based on a concentric cylinder model of transversally isotropic materials. A static friction coefficient $\mu$ will subsequently be calculated to validate the assumptions. At macroscopic scale, residual stresses will be investigated by recording the curvature evolution of asymmetric biocomposite laminates curvature after manufacturing and storing. Finally, a novel scenario will be discussed to explain natural fibre/matrix adhesion mechanisms.

\section{Material and Methods}

\subsection{Materials}

Biocomposites samples were manufactured with an unidirectional flax tape, $200 \mathrm{~g} / \mathrm{m}^{2}$ (from Lineo ${ }^{\circledR}$ ). Dew retted stems were mechanically scutched and hackled before being processed as a fibrous preform. The supplier claims that no treatment (chemical or physical) has been applied on these fibres. Polypropylene (PP) (PPC 3660 from Total Petrochemicals) and compatibilized PP with 4\% PP grafted maleic anhydride (MAPP) (Arkema Orevac CA 100) were extruded and film-cast. 
92 A stack of polymer films (PP + MAPP) and unidirectional flax-fibre tapes were

93

94

95

96

97 prepared in a metallic mold $\left(13 \times 13 \mathrm{~cm}^{2}\right)$. Unidirectional plies $\left(0\right.$ and $\left.90^{\circ}\right)$ and asymmetric laminates $\left[0_{3} ; 90_{3}\right]$ were manufactured. The thicknesses of longitudinal and transverse plies were similar providing an overall laminate thickness of $434 \pm 7 \mu \mathrm{m}$ after processing.

Biocomposites were manufactured with a dedicated hot pressing protocol, holding $190^{\circ} \mathrm{C}$ for 8 min with an incremental applied pressure up to 20 bar in order to maintain the fibre alignment. The cooling ramp was set to $15^{\circ} \mathrm{C} / \mathrm{min}$ in order to generate moderate residual stresses. The nominal flax fibre volume fraction was $60 \%$. Biocomposites plates were then cut to provide strips $\left(70 \times 10 \mathrm{~mm}^{2}\right)$ for curvature measurements.

\subsection{Gravimetric measurements}

Flax fibre preforms and MAPP films were weighed on a $10^{-4} \mathrm{~g}$ precision scale prior to processing. To determine initial water content, flax fibres were dried under vacuum at $105^{\circ} \mathrm{C}$ during $72 \mathrm{H}$. Weight variation was then measured on asymmetric biocomposites immediately after molding and during storage until constant weight was reached. Water content in flax fibres was determined knowing the initial fibre weight fraction in the composite and assuming that PP and MAPP were insensitive to water.

\subsection{Characterization of mechanical properties}

The tensile properties of biocomposites with flax fibre orientations set at $0^{\circ}\left(\mathrm{E}_{\mathrm{L}}\right)$ and $90^{\circ}\left(\mathrm{E}_{\mathrm{T}}\right)$ were measured separately on a MTS Synergie ${ }^{\mathrm{TM}} \mathrm{RT} / 1000$ test machine at 
113 controlled temperature $\left(23^{\circ} \mathrm{C}\right)$ with a crosshead displacement speed of $1 \mathrm{~mm} / \mathrm{min}$. An

114 axial extensometer with a gauge length of $25 \mathrm{~mm}\left(\mathrm{~L}_{0}\right)$ was used to measure the strain.

The bending curvature of asymmetric biocomposite strips after manufacturing was estimated by periodically taking pictures of one side of a clamped sample. Clamping length was reduced as much as possible $(\approx 2 \mathrm{~mm})$ to diminish the effect on stress estimation. The strip geometry (10 mm wide) was selected to reduce bifurcation effects as the thickness-to length ratio and the width-to-length ratio determine the final shape of the laminate [24]. Image analysis was performed using Image ${ }^{\circledR}$ software (National Institutes of Health, USA). The curvature was measured by fitting the time-evolution of the sample to a 'circle' function. Bending curvature (K) was calculated from the radius of the fitted circle.

\subsection{ESEM observation}

127 Environmental scanning electron microcopy (FEI) was used to measure flax fibre diameter variation as a function of relative humidity. In environmental mode, vapour pressure range was around 5-10 millibar and measurements were made at room temperature.

For each relative humidity (20-98\%), 5 single flax fibres were observed. Fibre diameter was measured at 3 different locations along the fibre and the results were then averaged. The swelling/ shrinkage coefficient $\beta$ is defined as the strain $\varepsilon$ induced by a variation of $1 \%$ of moisture content $\Delta \mathrm{m}$. 


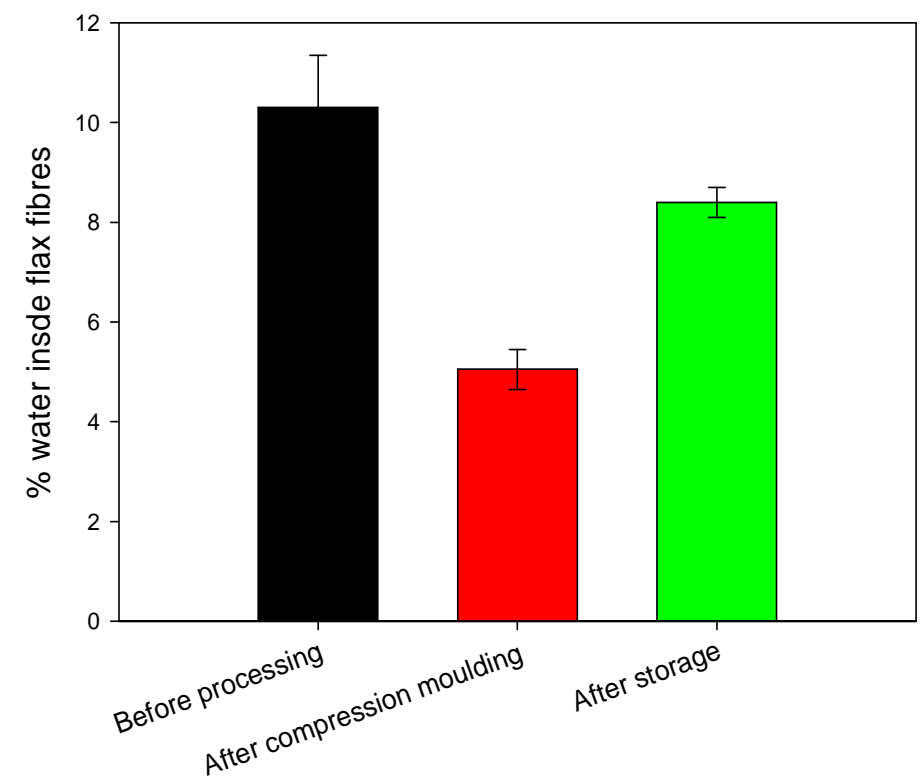

\section{Results and Discussion}

\subsection{Weight variation and hygroscopic expansion coefficient}

Flax fibres contain $10.3 \pm 1 \%$ of water in ambient conditions $\left(\mathrm{T}=23^{\circ} \mathrm{C}\right.$ and $\mathrm{RH}=$ 50\%). This water content evolves during the manufacturing step of thermoplastic biocomposites. On 60\%-vol flax/MAPP biocomposites, a weight reduction of $50 \%$ has been measured between initial preparation and the end of hot compression (Figure 1a).

Weight variation is assumed to be only due to water transfer (evaporation and condensation) within the flax fibres as the MAPP matrix is very apolar.

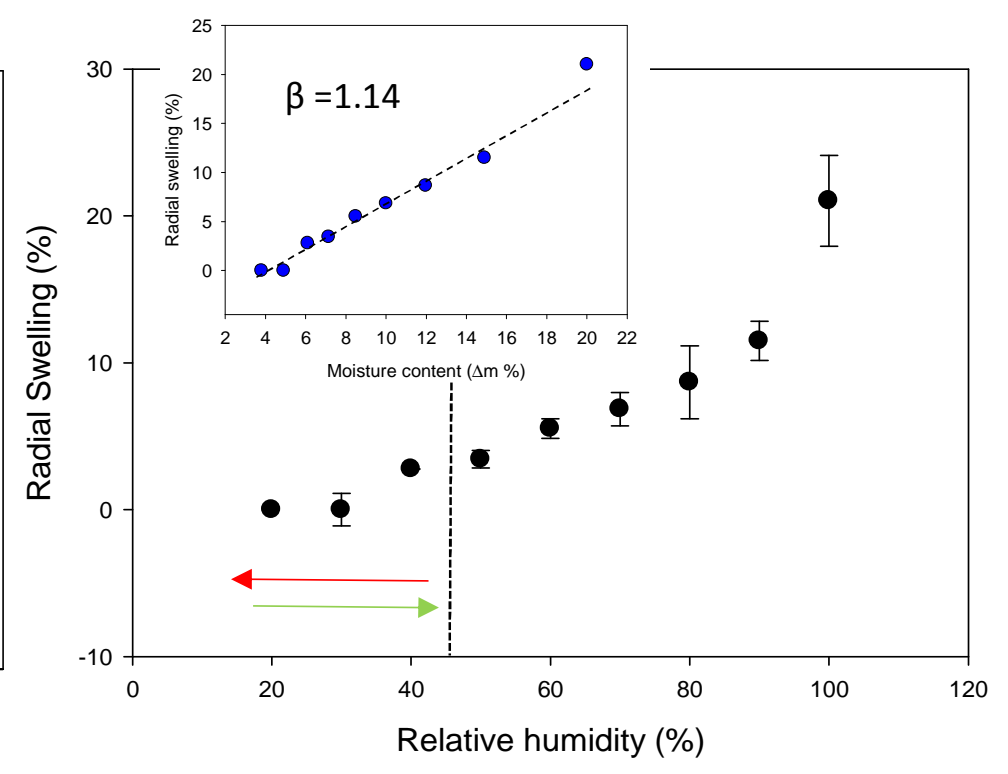

151 Figure 1 Evolution of water content within flax fibres during compression 152 moulding and storage ( $\mathrm{T}=\mathbf{2 3 ^ { \circ }} \mathrm{C}$ and $\mathbf{R H}=\mathbf{5 0 \%}$ during $\mathbf{7 2 0 0} \mathrm{min}$ ) (a), Evolution of 153 radial swelling of a single flax fibre as a function of relative humidity (b) Dotted 154 line indicates the border of the relative humidity during the process, Insert : 155 Evolution of radial swelling as a function of moisture content (from sorption 156 isotherm [25])

157 Thus, during compression molding (heating and cooling), there is a rise of temperature 158 to $190^{\circ} \mathrm{C}$ during 8 minutes, a subsequent reduction of relative humidity in the 
159

160

161

162

processing tool and applied pressure, which combine to remove water from the flax fibres. The amount of water inside the biocomposite is then $5.05 \pm 0.38 \%$ while fibre shrinkage occurs (Figure 1a). After 7200 minutes (5 days) of storage at $23^{\circ} \mathrm{C}$ and $50 \%$ $\mathrm{RH}$, the water content within the biocomposite increases to reach a constant value of $8.44 \pm 0.27 \%$ (Figure 1a) while thickness increases by $3.5 \pm 1.8 \%$. Radial swelling of embedded fibres occurs even if they do not recover their initial water content (Figure 1a). A hornification mechanism could partially explain this observation as already observed for flax fibres [26][27]. Indeed, when water is extracted from polysaccharides above a certain level, hydrogen bonds linking water to polysaccharides are disrupted and then rebuild within the polysaccharides. The consequence is a reduction of available hydroxyl groups and thus water sensitivity. Moreover, the surrounding matrix and its constraining effect on flax fibres reduce their accessibility to water but also their swelling [28][29]. The stress state at the fibre/matrix interface is likely to be modified while additional compressive stresses develop on fibres.

As observed in figure $1 \mathrm{~b}$, the radial swelling strain of flax fibre reaches a maximal value of $21 \pm 3 \%$ at $98 \%$ RH confirming results of Stuart et al. [30] and Pucci et al. [31].

Unlike the radial swelling evolution of flax fibre, over the relative humidity scale (20$98 \%$ ), its evolution with moisture content (data taken from [25]) appears quasi-linear $\left(R^{2}=0.99\right)$. Thus, a linear regression enables the radial hygroscopic coefficient $\beta f,{ }_{R}=$ $1.14 \varepsilon / \Delta \mathrm{m}$ to be estimated for a single flax fibre. Potential underestimation could be argued as ESEM measurements were performed at fibre scale while Dynamic Vapor Sorption (DVS) experiments were conducted at bundle scale [25]. Indeed pectin cements constituting middle lamellae and bundle cohesion are well known to promote water sorption [32]. Comparison with published data should be taken with caution as 
only wood fibres have been characterized and modelled. As they possess a larger lumen and a higher lignin content, which should influence swelling, wood fibres exhibit lower $\beta \mathrm{f}_{\mathrm{R}} \approx 0.3 \varepsilon / \Delta \mathrm{m}[33]$ and $0.45 \varepsilon / \Delta \mathrm{m}[34]$. However, an increase of hemicellulose hygroexpansion in the calculation strongly increases the hygroexpansion that reaches $\beta_{\mathrm{f}, \mathrm{R}}=1 \mathrm{\varepsilon} / \Delta \mathrm{m}$ for a similar microfibrillar angle [35]. This trend could be assumed to be relevant for flax fibres, which possess a larger amount of pectins and hemicellulose (Galactanes) than wood fibres.

Analyzing the different flax fibre expansion coefficients reveals that the hygroscopic effect is greatly superior to the thermal contribution (table 1).

Table 1 Radial thermal and hygroscopic expansion coefficients of flax single fibre compared to polypropylene

\begin{tabular}{|l|l|l|}
\hline & Single flax fibre & Polypropylene \\
\hline $\begin{array}{l}\text { Radial thermal expansion coefficient } \\
\alpha_{\mathrm{f}, \mathrm{T}}\left(10^{-6} /{ }^{\circ} \mathrm{C}\right)\end{array}$ & $78[36]$ & $120[4]$ \\
\hline $\begin{array}{l}\text { Radial hygroscopic expansion } \\
\text { coefficient } \beta_{\mathrm{f}, \mathrm{R}}(\varepsilon / \Delta \mathrm{m})\end{array}$ & 1.14 & - \\
\hline
\end{tabular}

\subsection{Multiscale evaluation of hygroscopic radial stress}

Evaluation of residual stresses with thermal and hygroscopic contributions is first performed at microscopic scale using a concentric cylinder model of transversally isotropic materials [37]. This model enables interfacial longitudinal and radial stresses to be calculated, including both the anisotropic properties of fibres and the thermal 
201

202

203

204

205

206

207

208

209

210

211

212

213

214

215

216

217

218

219

220

221

222

223

strain effects. Thermal strain describes the strain incompatibility between fibre and matrix as:

$\varepsilon_{\text {thermic }}=\left(\alpha_{f(L, R)}-\alpha_{m}\right) \Delta T$

Equation 1

With $\alpha$ the thermal expansion of fibre and matrix. $\mathrm{L}$ and $\mathrm{R}$ are longitudinal and radial directions. $\Delta \mathrm{T}$ is the temperature range over which thermal stresses are locked. For thermoplastic polymers, crystallization temperature is currently used [38]. For the MAPP matrix used here, $\mathrm{T}_{\mathrm{c}}=110^{\circ} \mathrm{C}$. Input data are taken from Table 1 and $\mathrm{E}_{\mathrm{fL}}=$ $55000 \mathrm{MPa}[3], \mathrm{E}_{\mathrm{fT}}=7000 \mathrm{MPa}[39]$.

The thermal radial stress obtained for MAPP/flax is $\sigma_{\text {rad Thermal }}=-3.65 \mathrm{MPa}$. This negative value can be explained by the higher value of $\alpha_{\mathrm{m}}$ compared to $\alpha_{\mathrm{fT}}$ and $\alpha_{\mathrm{fL}}$ and means that a compressive state occurs in the fibre/matrix interface area. These values are close to those published elsewhere on PA11/Flax [11] and PP/jute [4].

Determination of the static friction coefficients $\mu$, obtained from the ratio between interfacial tangential stress (IFSS) and normal stress (radial residual stress) evaluated by eq 2. provide values around 0.65 for glass/PP [16] and 0.6 for carbon/epoxy [17].

$\tau_{\text {app }}=\mu . \sigma_{\text {Residual }}$

Equation 2

Using $\tau_{a p p}$ for MAPP/flax of 10.6 $\pm 2.7 \mathrm{MPa}[40]$ and $\sigma_{\text {residual }}=3.4 \mathrm{MPa}$ leads to an anomalous value of $\mu=3.11$. This high value of $\mu$ (>1) can be attributed to a missing source of residual stress [15].

As shown in Figure $1 \mathrm{~b}$ and in Table 1, hygroscopic expansion of flax fibres is significantly higher than their thermal expansion. Thus, radial stress can be calculated using the Wagner and Nairn model [37] where thermal strains are substituted by hygroscopic strain: 
225 With $\beta$ the hygroscopic expansion of fibre and matrix. L and $\mathrm{R}$ are longitudinal and

226 radial directions. $\beta_{\mathrm{f}, \mathrm{L}}$ has not been measured here but is assumed to be close to zero

227 similarly to wood fibres [33]. $\beta_{\mathrm{m}}$ for MAPP is also assumed to be negligible and $\Delta \mathrm{m}$ is the moisture content difference between the end of compression moulding and storage, i.e. 3.4\%. The stiffness of flax fibres and MAPP are assumed to be constant over such a moisture content range [41]. Thus, $\sigma_{\text {rad, hygrosocpic }}=26.7 \mathrm{MPa}$. Calculating the overall radial stress as the addition of the contribution of the tensile hygroscopic stress $\sigma_{\text {rad }}$ hygroscopic to the compressive thermal value $\sigma_{\text {rad thermal, leads to } \sigma \text { global }}=\sigma_{\text {rad hygroscopic }}+\sigma$ rad thermal, $=26.7-3.65=23.05 \mathrm{MPa}$.

Validation is then performed by calculating the static friction coefficient $\mu$ (Eq. 2) and Epoxy/glass [17]. Thus, hygroscopic strains could be considered as the missing source that needs to be taken into account in evaluating the IFSS of natural fibre systems.

Microscopic evaluation of $\sigma_{\text {rad }}$ by a micromechanical model was performed on an idealized cylinder geometry with very low fibre content $\left(\mathrm{v}_{\mathrm{f}} \approx 1 \%\right)[42]$. Therefore, asymmetric biocomposites laminates $\left[0_{3} / 90_{3}\right]$ were also used, to assess the development of residual stresses at the macroscale.

243 Once the compression molding step is finished, these biocomposites show a significant 244 curvature due to the thermal expansion and hygroscopic shrinkage of $90^{\circ}$ oriented plies 245 (Figure 2). After 5 days of storage at 50\% RH and ambient temperature, the curvature of the biocomposite reaches a stationary position (Figure 2) with a slightly inversed 
247

248

249

250

251

252

253

254

255

256

257

258

259

260

261

262

263

264

265

266

267

268

curvature. Stress released by creep mechanisms is assumed to be negligible during this time period.

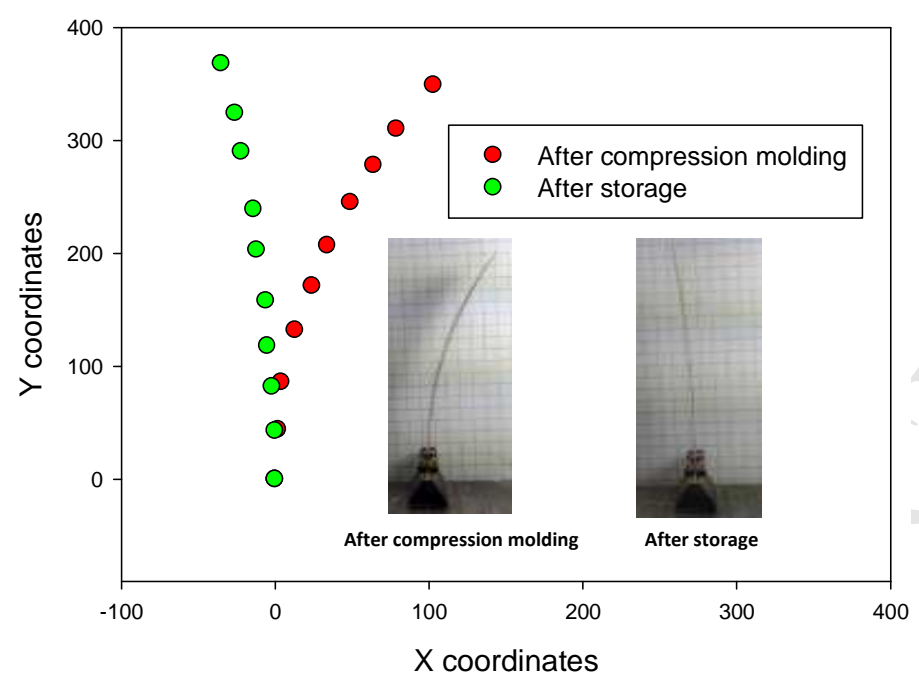

Figure 21 Evolution of asymmetric biocomposite laminate $\left[0_{3} / 90_{3}\right]$ curvature after compression molding and storage at room temperature and $\mathbf{R H}=50 \%$. (For interpretation of the references to color in this figure legend, the reader is referred to the web version of this article)

Residual stresses generated during processing and during storage could be estimated separately from the curvature value at each step using equation 4 [43]:

$\sigma_{22}=\sigma_{\text {radial }}=\frac{E_{11} \cdot E_{22}}{E_{11}+E_{22}} \frac{t}{\Delta \rho}\left(\frac{1}{2}+\frac{1}{24}\left(2+\frac{E_{11}}{G_{12}}+\frac{E_{22}}{G_{12}}\right)\right.$ Equation 4

With $\mathrm{t}$ the thickness of the sample $(\mathrm{t}=0.450 \mathrm{~mm}), \Delta \rho$ the differential curvature radius $\left(\Delta \rho_{\text {after compression }}=154.3 \pm 18 \mathrm{~mm} ; \Delta \rho_{\text {after storage }}=126 \pm 12 \mathrm{~mm}\right), \mathrm{E}_{11}$ and $\mathrm{E}_{22}$ are the values of longitudinal modulus $\left(\mathrm{E}_{11}=30950 \pm 2107 \mathrm{MPa}\right)$ and transverse modulus $\left(\mathrm{E}_{22}\right.$ $=1791 \pm 180 \mathrm{MPa}), \mathrm{G}_{12}$ is the in-plane shear modulus estimated by rule of mixture giving $\mathrm{G}_{12}=1041 \mathrm{MPa}$ using $\mathrm{G}_{\mathrm{flt}}=2500 \mathrm{MPa}[44]$ and $G_{m}=\frac{\sigma_{m}}{2(1+\vartheta)}$ with $\sigma_{\mathrm{m}}=1500 \pm$ $100 \mathrm{MPa}$. No significant difference of mechanical properties of the composite is assumed between the end of compression and the end of storage. 
269 Consequently, the radial stress developed during compression molding is the sum of

270 thermal and hygroscopic contributions and reaches a value of $9.3 \pm 0.8 \mathrm{MPa}$. Storage at

$27150 \% \mathrm{RH}$ generates stress of $11.3 \pm 1.1 \mathrm{MPa}$ due to hygroscopic expansion of flax fibres.

272 Calculation of the overall residual stress is therefore the sum of both contribution and is

$27320.6 \mathrm{MPa}$ which is in a similar range to the values obtained by micromechanical

274 modelling.

275

276

277

278

279

280

281

282

283

284

285

286

287

288

289

290

291

\section{4-Discussion}

A scenario is proposed to describe the contribution of different residual stresses in natural fibre/thermoplastic polymer system that control the interfacial shear strength (Figure 3).

\section{Heating}

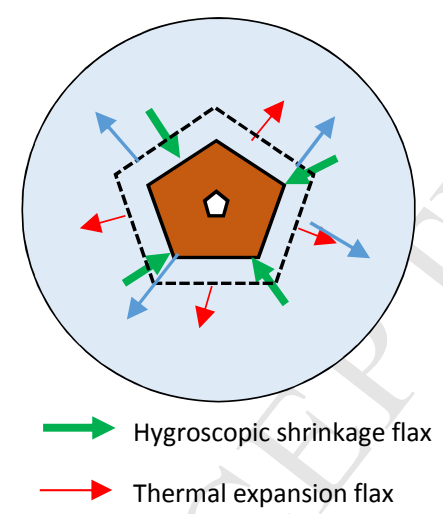

$\longrightarrow$ Thermal expansion PP
Cooling

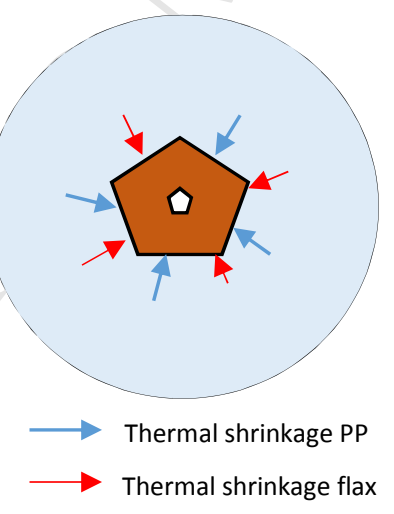

Storage at $\mathbf{R H}=\mathbf{5 0} \%$

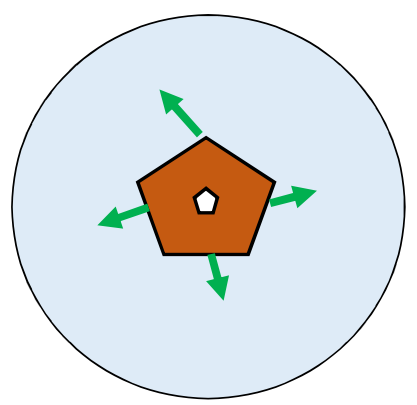

$\longrightarrow$ Hygroscopic expansion flax

Figure 3 Principle of residual stress generation at plant/matrix interface. Thickness of arrow proportional to the magnitude of stress (For interpretation of the references to color in this figure legend, the reader is referred to the web version of this article)

During processing, flax fibres will mainly shrink due to water evaporation rather than expand thermally. During compression molding, viscous polypropylene matrix will fill 
292

293

294

295

296

297

298

299

300

301

302

303

304

305

306

307

308

309

310

311

312

313

314

315

all interstices of the biocomposite. During the cooling step, fibre and matrix will shrink to different extents according to their thermal expansion coefficients. Thermal and hygroscopic stresses will be generated at the fibre/matrix interface. During storing at $50 \% \mathrm{RH}$, flax fibres will swell to a larger extent than the matrix. Hygroscopic stress will be produced.

As shown in Table $1 \alpha_{\mathrm{f}, \mathrm{L}, \mathrm{R}}$ is lower than $\alpha_{\mathrm{m}}$ which yields an initial compressive stress state which is reduced when temperature increases [1]. As $\beta_{\mathrm{f}, \mathrm{L}, \mathrm{R}}$ is much higher than $\beta_{\mathrm{m}}$, $\alpha_{\mathrm{f}, \mathrm{L}, \mathrm{R}}$ and $\alpha_{\mathrm{m}}$, an initial tensile stress state will appear at the fibre /matrix interface. Drying these materials after processing will therefore reduce the radial stresses, while increasing humidity and moisture content will increase radial stress and thus raise IFSS, to a limit that is still unknown.

\section{5- Conclusion}

The present article has shown that during manufacturing and storage of thermoplastic biocomposites, a weight variation is observed, attributed to a modification of water content in the composite and thus in flax fibres. The hygroscopic radial expansion coefficient of flax fibre has been estimated and it is many orders of magnitude higher than the thermal expansion.

Estimation of residual stress using only thermal strain is not correct, as the static friction coefficient reaches an anomalous value of 3.11. Taking the hygroscopic strain into account, results in the residual stresses increasing significantly, from -3.65 to 23.05 MPa which may lead to damage mechanism. Including the overall residual stress in the calculation of $\mu$ leads to a more satisfactory value of 0.46 .

As micromechanical modelling and an experimental approach converge to a similar and more relevant value of static friction coefficient, the hygroscopic behavior of natural 
316 fibres must be added to the thermal response in order to describe their interfacial

317 performance correctly. For natural fibres and flax for instance, the high contribution of

318 hygroscopic stress due to flax fibre expansion controls the stress state at the fibre/matrix

319 interface and thus the performance.

320 This information provides a new insight into the plant fibre/matrix interface bonding

321 mechanism. Indeed, initially considered as a drawback, the moisture sensitivity of flax

322 fibres could be turned into an advantage if radial stress can be generated. In this context,

323 the benefits of reducing their water affinity by different kinds of treatments appear to be

324 questionable. From an industrial point of view, the effect of a degassing that releases a

325 large amount of water may be of interest for further study as it may amplify the swelling 326 of plant fibres.

[1] Thomason JL, Yang L. Temperature dependence of the interfacial shear strength

[3] Baley C, Bourmaud A. Average tensile properties of French elementary flax

[4] Thomason J. Dependence of interfacial strength on the anisotropic fiber properties of jute reinforced composites. Pollymer Compos 2009;31. 
338 [5] Gentles F, Anderson J, Thomason J. Characterisation of the transverse thermoelastic properties of natural fibres used in composites. 14th Eur. Conf. Compos. Mater. ECCM14, 2010, p. http://strathprints.strath.ac.uk/27074/1/strathpri.

[6] Morgan RJ, Pruneda CO SW. The relationship between the physical structure and the microscopic deformation and failure processes of poly(para-phenylene

[10] Graupner N, Rößler J, Ziegmann G, Müssig J. Fibre/matrix adhesion of cellulose fibres in PLA, PP and MAPP: A critical review of pull-out test, microbond test and single fibre fragmentation test results. Compos Part A Appl Sci Manuf 2014;63:133-48. doi:http://dx.doi.org/10.1016/j.compositesa.2014.04.011.

[11] Le Duigou A, Bourmaud A, Gourier C, Baley C. Multi-scale shear properties of flax fibre reinforced polyamide 11 biocomposites. Compos Part A Appl Sci 
Manuf 2016;85:123-9. doi:10.1016/j.compositesa.2016.03.014.

362

363

364

365

366

367

368

369

370

371

372

373

374

375

376

377

[12] Le Duigou A, Kervoelen A, Le Grand A, Nardin M, Baley C. Interfacial properties of flax fibre-epoxy resin systems: Existence of a complex interphase. Compos Sci Technol 2014;100:152-7. doi:10.1016/j.compscitech.2014.06.009.

[13] Baley C, Busnel F, Grohens Y, Sire O. Influence of chemical treatments on surface properties and adhesion of flax fibre-polyester resin. Compos Part A Appl Sci Manuf 2006;37:1626-37. doi:10.1016/j.compositesa.2005.10.014.

[14] Mikhin NM AN. dependence of the coefficient of external static friction on temperature. Investig Sov Phys J 1974;17:873-5.

[15] J.L. Thomason, Yang L. Temperature dependence of the interfacial shear strength in glass-fibre epoxy composites. Compos Sci Technol 2014;96:7-12.

[16] G.E. Schoolenberg. Polypropylene: structure, blends and composites. J KargerKocsis (Ed), Chapmann Hall [Chapter 36] n.d.

[17] M. Detassis, A. Pegoretti CM. Effect of temperature and strain rate on interfacial shear stress transmission in carbon/epoxy model composites. Compos Sci Technol 53AD;1995:39-46.

[18] Parlevliet P, Bersee H and BA. Residual stresses in thermoplastic composites--A study of the literature--Part I: Formation of residual stresses. Comp Part A Appl Sci Manuf 2006;37:1847-57.

[19] M Gigliotti, F Jacquemin, Vautrin A. Assessment of approximate models to evaluate transient and cyclical hygrothermoelastic stress in composite plates. Int $\mathbf{J}$ Solids Struct 2007;44:733-59. 
383

384

385

386

387

388

389

390

391

392

393

394

395

396

397

398

399

400

401

402

403

404

[20] M. Gigliotti, M.R. Wisnom KDP. Development of curvature during the cure of AS4/8552 [0/90] unsymmetric composite plates. Compos Sci Technol 2003;63:187-97.

[21] Le Duigou A, Castro M. Moisture-induced self-shaping flax-reinforced polypropylene biocomposite actuator. Ind Crops Prod 2015;71:1-6. doi:10.1016/j.indcrop.2015.03.077.

[22] Le Duigou, A., Castro M. Hygromorph BioComposites : Effect of fibre content and interfacial strength on the actuation performances. Ind Crop Prod 2017;99:142-9.

[23] Almgren KM, Gamstedt EK. Characterization of Interfacial Stress Transfer Ability by Dynamic Mechanical Analysis of Cellulose Fiber Based Composite Materials. Compos Interfaces 2010;17:845-61. doi:10.1163/092764410X539235.

[24] Jeronimidis G PA. Residual-stresses in carbon fiber- thermoplastic matrix laminates. J Compos Mater 1988;22:401-15.

[25] Hill CAS, Norton A, Newman G. The water vapor sorption behavior of natural fibers. J Appl Polym Sci 2009;112:1524-37. doi:10.1002/app.29725.

[26] Diniz J. M. B. F., Gil M. H. CJ a. a. M. Hornification-its origin and interpretation in wood pulps. Wood Sci Technol 2004;37:489-94.

[27] Gourier C, Le Duigou A, Bourmaud A, Baley C. Mechanical analysis of elementary flax fibre tensile properties after different thermal cycles. Compos Part A Appl Sci Manuf 2014;64:159-66. doi:10.1016/j.compositesa.2014.05.006.

[28] Le Duigou A, Castro M. Evaluation of force generation mechanisms in natural, 
passive hydraulic actuators. Sci Rep 2016;18105.

[29] Joffre T, Wernersson ELG, Miettinen A, Luengo Hendriks CL, Gamstedt EK. Swelling of cellulose fibres in composite materials: Constraint effects of the surrounding matrix. Compos Sci Technol 2013;74:52-9. doi:10.1016/j.compscitech.2012.10.006.

[30] Stuart T, McCall RD, Sharma HSS, Lyons G. Modelling of wicking and moisture interactions of flax and viscose fibres. Carbohydr Polym 2015;123:359-68. doi:10.1016/j.carbpol.2015.01.053.

[31] MF Pucci, PJ Liotier SD. Capillary wicking in flax fabrics - Effects of swelling in water. Colloids Surfaces A Physicochem Eng Asp 2016;498.

[32] Martin N, Davies P, Baley C. Comparison of the properties of scutched flax and flax tow for composite material reinforcement. Ind Crops Prod 2014;61:284-92. doi:10.1016/j.indcrop.2014.07.015.

[33] Joffre T, Neagu RC, Bardage SL, Gamstedt EK. Modelling of the hygroelastic behaviour of normal and compression wood tracheids. J Struct Biol 2014;185:89-98. doi:10.1016/j.jsb.2013.10.014.

[34] T. Joffre, P. Isaksson, P.J.J. Dumont, S.Rollanddu Roscoat SS, Gamstedt LO\& EK. A Method to Measure Moisture Induced Swelling Properties of a Single Wood Cell. Exp Mech 2016.

[35] E Marklund JV. Modeling the hygroexpansion of aligned wood fiber composites. Compos Sci Technol 2009;69:1108-14.

[36] Cichocki Jr. FR, Thomason JL. Thermoelastic anisotropy of a natural fiber. 
427

428

429

430

431

432

433

434

435

436

437

438

439

440

441

442

443

444

445

446

447

448

Compos Sci Technol 2002;62:669-78.

[37] H. D. Wagner \& J. A. Nairn. Residual thermal stresses in three concentric transverselty isotropic cylinders: Application to thermoplastic-matrix composites containing a transcrystalline interphase. Compos Sci Technol 1997;57:1289-302.

[38] J.A. Nairn PZ. Matrix solidification and the resulting residual thermal stresses in composites. J Mater Sci 1985;20:355-67.

[39] Baley C, Perrot Y, Busnel F, Guezenoc H, Davies P. Transverse tensile behaviour of unidirectional plies reinforced with flax fibres. Mater Lett 2006;60:2984-7. doi:10.1016/j.matlet.2006.02.028.

[40] J Merotte A le Duigou, A. Kervoelen, A. Bourmaud, K. Behlouli, O. Sire and CB. Influence of fibre/matrix interface bond and fibre properties on non-woven vegetal fibre composites. Comp Part A Appl Sci Manuf n.d.

[41] Thuault A, Eve S, Blond D, Gomina M, Breard J. Effects of the hygrothermal environment on the mechanical properties of flax fibres. J Compos Mater 2014;48:1699-707.

[42] L.Yang JLT and. Temperature dependence of the interfacial shear strength in glass-fibre epoxy composites. Compos Sci Technol 2014;96:7-12.

[43] PP. Parlevliet, HE.N. Bersee, AB. Residual stresses in thermoplastic composites-A study of the literature-Part II: Experimental techniques. Comp Part A Appl Sci Manuf 2007;38:651-5.

[44] Baley C Kervoëlen A Le Duigou A Goudenhooft C Bourmaud A. Is the low shear modulus of flax fibres an advantage for polymer reinforcement? Mater Lett 
449 2016;185:534-6.

450

451

452

453 